\title{
SISTEMATIZAÇÃO DOS DOCUMENTOS DE QUALIFICAÇÃO DOS FORNECEDORES CRÍTICOS PARA O MEIO AMBIENTE E QUALIDADE*
}

Andreza Aparecida de Miranda ${ }^{1}$ Daira Alves de Almeida²

\section{Resumo}

No mercado atual a organização que possui certificação ISO tem ganhos significativos de competitividade e credibilidade. A Companhia Siderúrgica Nacional é uma empresa que possui tanto a certificação ISO 14001 quanto ISO 9001 e TS16949. Para a manutenção dessas certificações é necessário que exista uma gestão sobre a aplicabilidade dessas normas e uma exigência legal é a qualificação dos seus fornecedores críticos para o Meio Ambiente e para Qualidade. O objetivo deste trabalho consiste em apresentar o modelo de monitoramento destes fornecedores nos quesitos performance de Entrega, performance de Qualidade e arquivamento das documentações legais. A Diretoria de Suprimentos atua de forma corporativa em 12 sites, e semestralmente gera relatórios para realizar este monitoramento e essa documentação gerada era arquivada em diversas pastas (em papel) em um único site, o que dificultava a consulta de funcionários que estivessem em outro site nos momentos de auditoria. O novo modelo contempla a ferramenta utilizando o próprio ERP, SAP/R3 que possibilita a consulta da documentação necessária, do fornecedor que desejar, de qualquer site, a qualquer momento. Essa ferramenta tem como objetivo agilizar a chegada de informação para quem precisar, em tempo real.

Palavras-chave: Sistematização; Qualificação; Meio ambiente; Qualidade.

\section{SISTEMATIZATION OF THE CRITIC SUPPLIERS QUALIFICATION DOCUMENTS TO THE ENVIRONMENT AND QUALITY}

\begin{abstract}
At the current Market, the organization that has the ISO certification has significant gains of competitiveness and credibility. "CSN" is a company that has both certifications: ISO 14001 and ISO 9001 and TS16949. To keep these certifications it is necessary to exist a management of these directions applicability, and a legal exigency is its critics suppliers qualifications to the Environment and to the Quality. This assignment goal is to present these suppliers monitoring model in the following inquiries: delivery performance, quality performance and the legal documentation filing. The Accessory Direction acts in a corporative manner in 12 sites, and half-yearly generates written reports to put into practice these monitoring and this generated documentation was filed in several files (in paper) in a single site, what makes the consult more difficult to the employees who were in another site at the auditing moment. The new model contemplates the tool using the programs ERP, SAP/RJ, that allows the needed documentation, the needed supplier of whatever site, whenever wanted. This tool has as a goal to speed up the information for whoever need, in a real time.
\end{abstract}

Keywords: Systematization; Qualification; Environment; Quality.

1 Bióloga, Analista de Administração de Materiais, Gerência Geral de Administração de Materiais, Companhia Siderúrgica Nacional, Volta Redonda, Rio de Janeiro, Brasil.

2 Arquiteta, Coordenadora de Recicláveis e Obras, Gerência Geral de Administração de Materiais, Companhia Siderúrgica Nacional, Volta Redonda, Rio de Janeiro, Brasil.

\footnotetext{
* Contribuição técnica ao 33 Seminário de Logística - Suprimentos, PCP, Transportes, 13 a 16 de maio de 2014, São Paulo, SP, Brasil.
} 


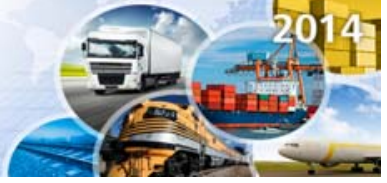

\section{INTRODUÇÃO}

A Companhia Siderúrgica Nacional atualmente possui Certificação na ISO 9001, ISO 14001 e ISO TS16949 e conforme item das normas em questão todos seus fornecedores devem possuir qualificação ambiental e de qualidade.

Para manter estas certificações, a organização, dentre outros itens, deve avaliar e selecionar fornecedores com base na sua capacidade em fornecer produtos de acordo com os requisitos da organização o que gera grande quantidade de documentos a serem analisados e arquivados.

O processo consistia em identificar os fornecedores, solicitar as devidas documentações e avaliá-las. Ao final do processo toda documentação era armazenada em pastas que ocupavam espaço físico, tínhamos gastos com impressão e principalmente o acesso a esta documentação era limitado, pois em momentos de auditoria em outros sites, na necessidade de consulta de alguma documentação, a mesma era escaneada e enviada ao solicitante por e-mail e devido a lentidão deste processo, identificamos a necessidade de melhoria e com isso buscamos uma ferramenta que nos ajudasse a gerenciar essa atividade.

\section{MÉTODOLOGIA}

Neste trabalho foram combinadas as seguintes modalidades de pesquisa, segundo Yin [1]:

- Documental: analisados dados e documentos dia à dia;

- Descritiva: levantados dados e informações sobre a empresa.

- Histórica: apresentados fatos ocorridos nos últimos 3 anos.

- Levantamentos: solicitadas informações aos responsáveis pelas áreas de Cadastro de Fornecedor, Gestão da Qualidade e Gestão Ambiental.

Foram também utilizados os métodos de pesquisa objetivo e histórico de investigação.

As técnicas de pesquisa que foram utilizadas nesta investigação são entrevistas com os Gerentes das Áreas envolvidas e arquivos particulares da empresa.

\section{RESULTADOS E DISCUSSÃO}

\subsection{Evolução Histórica}

Antes de acontecer o Cadastro do Fornecedor os materiais que influenciam na qualidade e/ou meio ambiente a área de Cadastro de Fornecedores solicita toda documentação necessária, após o recebimento dos documentos os mesmos são enviados para Volta Redonda para arquivamento e em seguida a equipe do Cadastro de Fornecedores efetiva o cadastramento do fornecedor no SAP R/3.

Já a equipe de Volta Redonda (responsável pela manutenção desses fornecedores) geram um relatório semestralmente, onde identificávamos os fornecedores com documentação vencida. Para fornecedores que apresentam documentação vencida é feito contato através de telefone ou e-mail solicitando o envio da documentação.

Esta documentação chega às mãos dessa equipe (conhecida internamente como contraparte de Meio Ambiente e Qualidade da Diretoria de Suprimentos) que arquivava a documentação em pastas, o que ocupava muito espaço.

Quando estas documentações eram solicitadas em períodos de auditoria por outros sites do grupo CSN, havia uma dificuldade em encontrar e enviar esta

\footnotetext{
* Contribuição técnica ao $33^{\circ}$ Seminário de Logística - Suprimentos, PCP, Transportes, 13 a 16 de maio de 2014, São Paulo, SP, Brasil.
} 


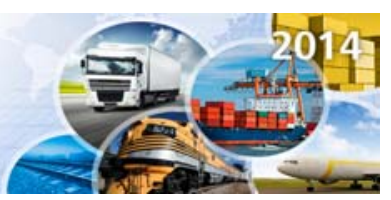

documentação, pois em alguns casos a auditoria era realizada em outros estados do país. Neste caso o documento era escaneado e enviado ao solicitante.

A grande dificuldade encontrada neste processo era demora no recebimento destas informações e também ocupava espaço e gerava custos de impressões em torno de $\mathrm{R} \$ 600,00 /$ mês.

$\mathrm{Na}$ Figura 1 é possível visualizar um dos armários destinados para guarda dos documentos de qualificação dos fornecedores do grupo CSN.

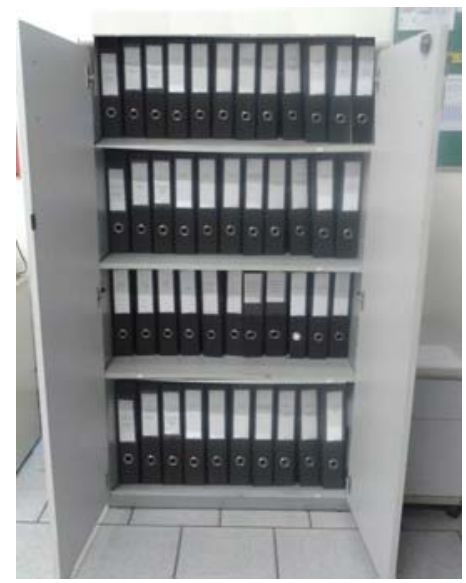

Figura 1. Armário destinado à guarda dos documentos de qualificação dos Fornecedores.

Depois de alguns estudos, identificamos a possibilidade de realizarmos esta atividade utilizando o sistema SAP R3, pois teríamos agilidade em todo o processo de consulta na documentação de fornecedores.

\subsection{Descrição da Atividade}

Após o cadastro do fornecedor, semestralmente o contraparte da Qualidade da DSUP solicita a Gerência de Planejamento de Materiais o relatório de "Itens ISO" onde consta a listagem de todas as entregas de materiais críticos tanto para o Meio Ambiente quanto para a Qualidade.

Logo após a emissão deste relatório, realizamos a consulta da documentação de todos os fornecedores através da transação XK03 no sistema SAP R3, conforme Figura 2 a 5.

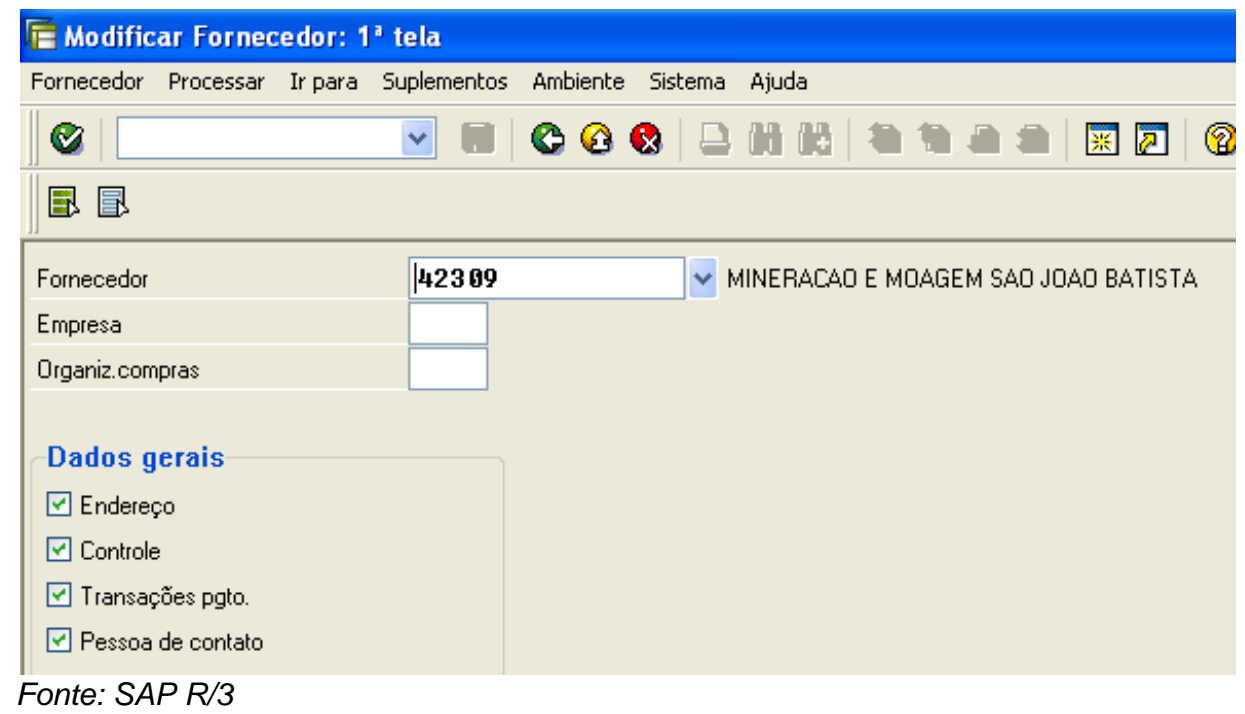

Figura 2. Tela inicial para inserção dos dados do fornecedor.

\footnotetext{
* Contribuição técnica ao $33^{\circ}$ Seminário de Logística - Suprimentos, PCP, Transportes, 13 a 16 de maio de 2014, São Paulo, SP, Brasil.
} 


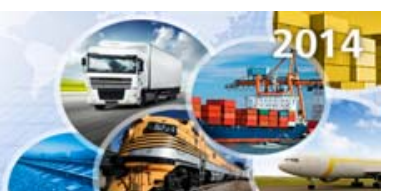

辰 Modificar Fornecedor: Endereço

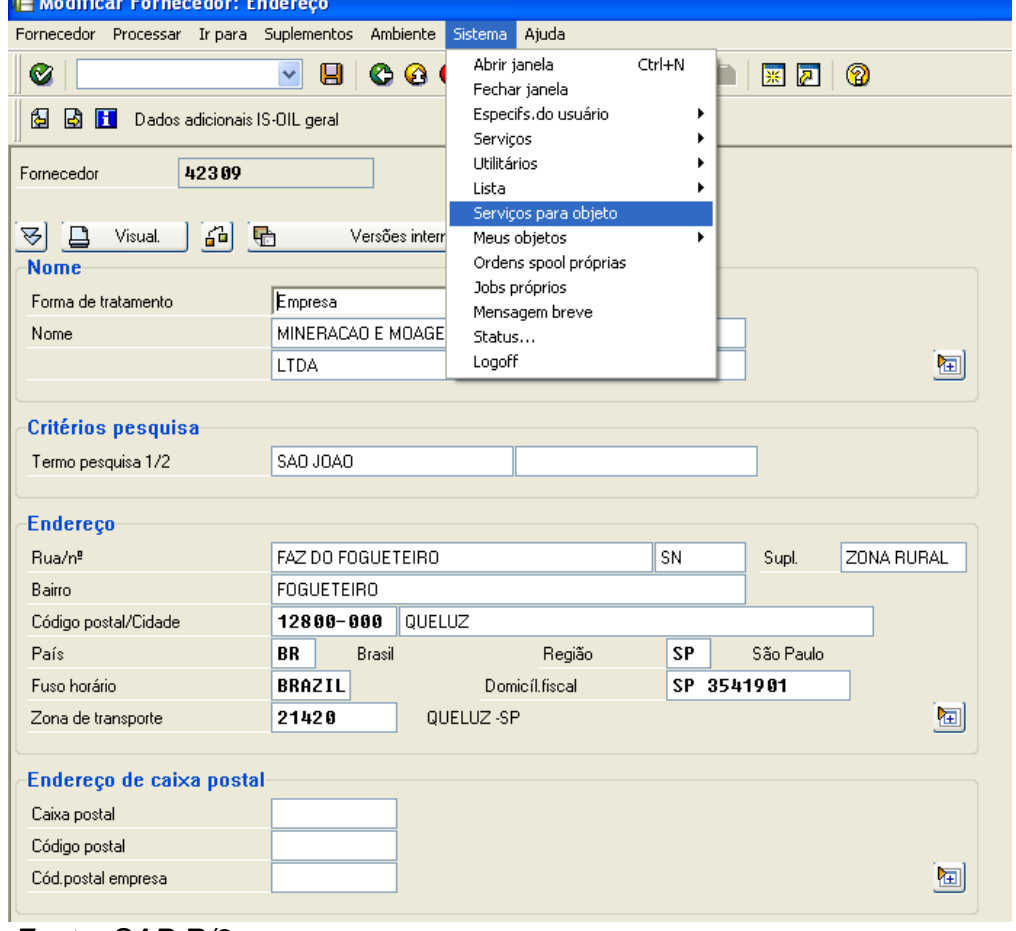

Fonte: SAP R/3

Figura 3. $2^{\mathrm{a}}$ tela para inserção dos dados do fornecedor.

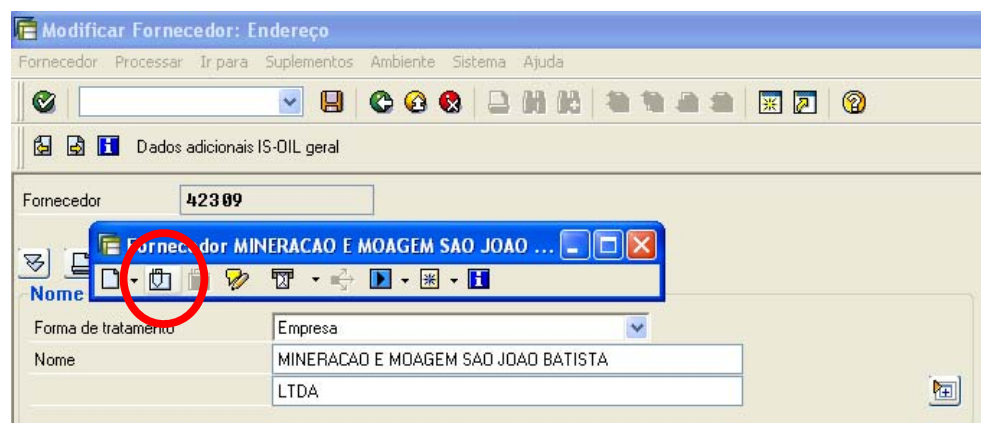

Fonte: SAP R/3

Figura 4. Tela para anexar a documentação do fornecedor.

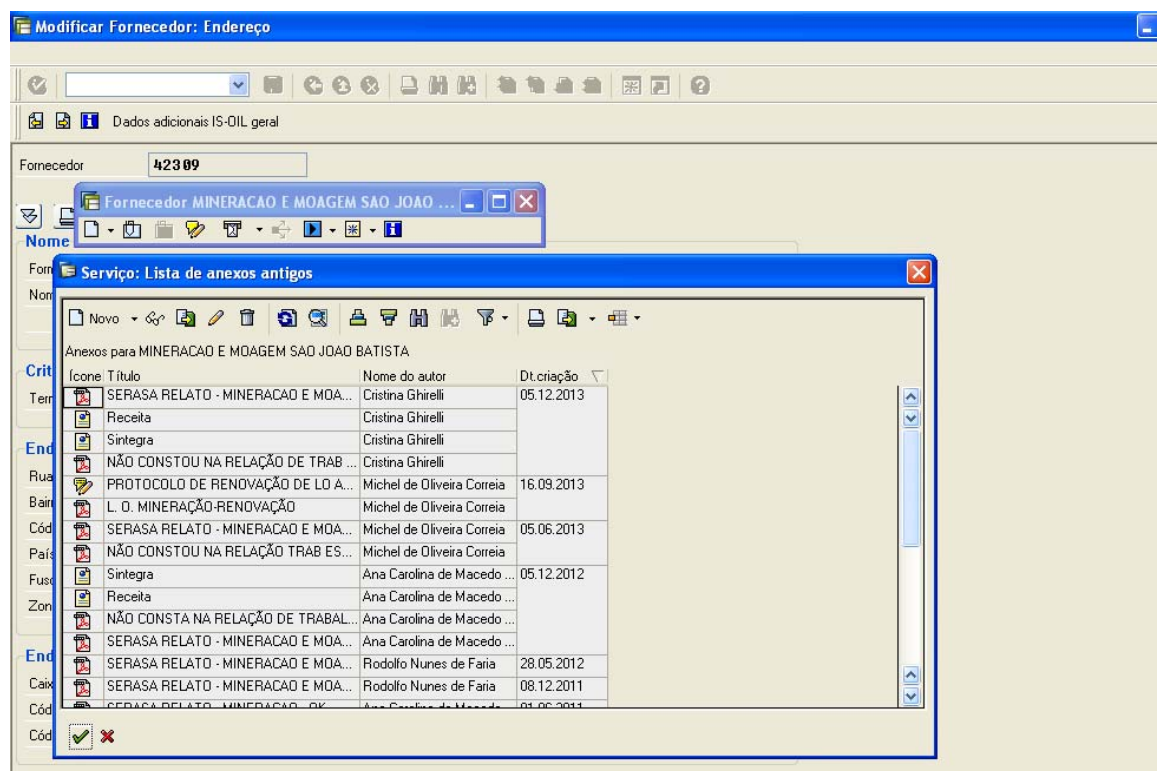

Fonte: SAP R/3

Figura 5. Tela com a listagem das documentações que o fornecedor possui.

* Contribuição técnica ao $33^{\circ}$ Seminário de Logística - Suprimentos, PCP, Transportes, 13 a 16 de maio de 2014, São Paulo, SP, Brasil. 


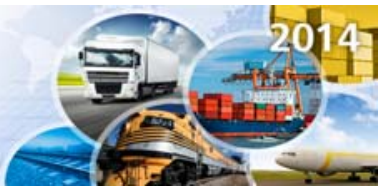

Logo após levantarmos a validade dos documentos (Figura 6), realizamos um contato com os fornecedores através de e-mail solicitando o envio dos documentos atualizados.

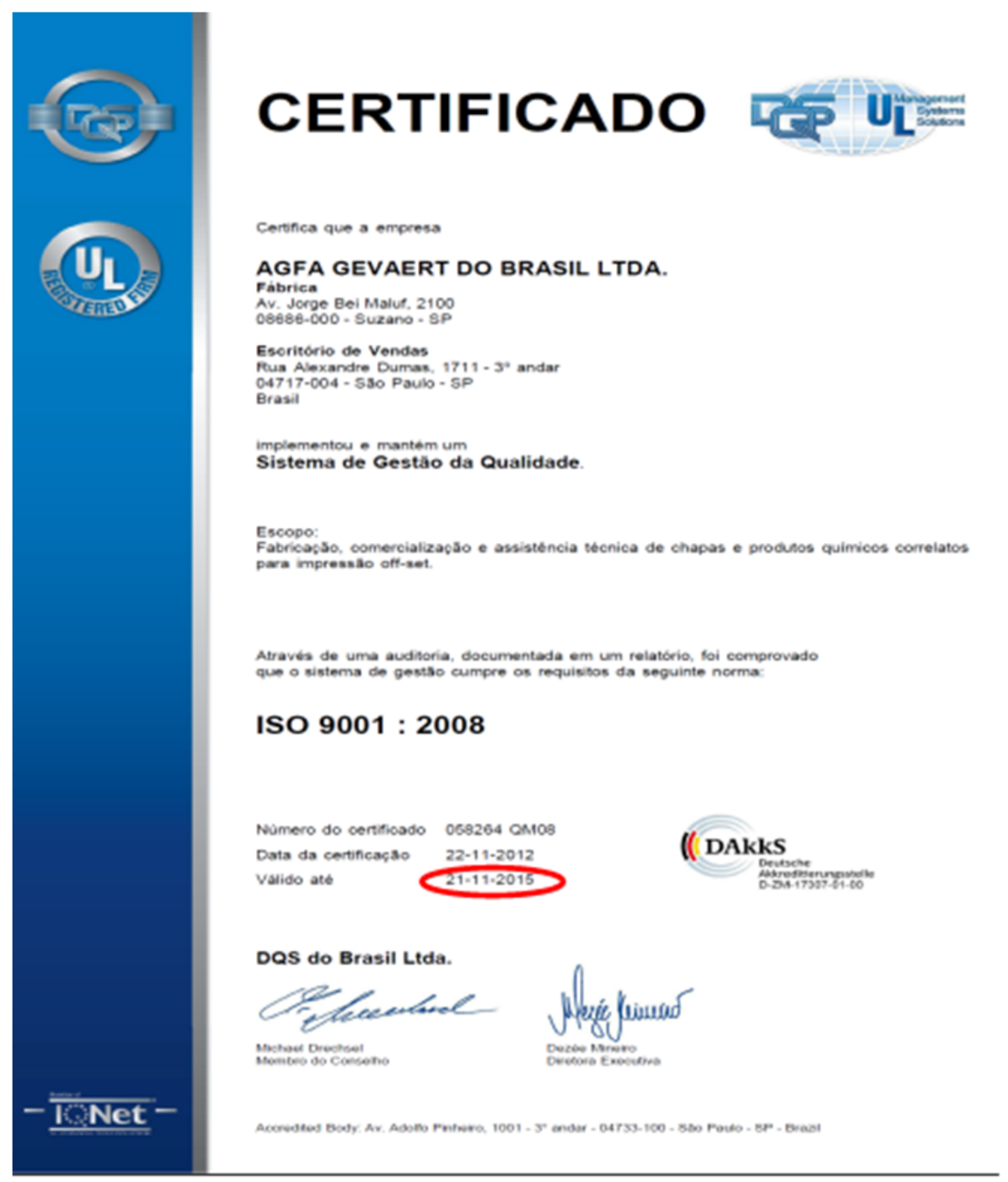

Fonte: Site da empresa AGFA Gevaert do Brasil.

Figura 6. Exemplo de documento analisado.

Ao recebermos a documentação, após conferência se o documento esta atendendo nossa necessidade, inserimos o documento e a validade no sistema SAP R3 ficando disponível para consulta aos envolvidos no processo.

\section{RESULTADOS DO PROJETO}

Após implantação do projeto identificou-se ganhos qualitativos e quantitativos: $1^{\circ}$ ganho - Ganho Qualitativo:

- Maior agilidade nas informações;

- Rastreabilidade da documentação em sistema integrado e homologado pela empresa;

- Liberação de espaço físico (local onde era estocado toda a documentação);

- Maior assertividade na apresentação da documentação no momento da auditoria;

- Maior Controle no sistema de gestão dos fornecedores.

\footnotetext{
* Contribuição técnica ao $33^{\circ}$ Seminário de Logística - Suprimentos, PCP, Transportes, 13 a 16 de
} maio de 2014, São Paulo, SP, Brasil. 
$2^{\circ}$ ganho - Ganho Quantitativo:

- Redução no custo de cópias (mensurar valor R\$600,00/mês);

\section{CONCLUSÃO}

O trabalho teve como objetivo mostrar o quanto é importante à gestão documental de uma empresa, mas para isso a empresa deve estar estruturada, no estudo de caso em questão foi possível apresentar a implantação de uma sistemática que trouxe melhor rastreabilidade, redução de custo, maior agilidade e a garantia de um sistema de gestão da qualidade e meio ambiente eficaz.

Dessa forma, considera-se que todos os objetivos propostos foram alcançados com a confirmação dos ganhos obtidos sejam ganhos quantitativos, sejam ganhos qualitativos. Hoje a Companhia Siderúrgica Nacional tem sua documentação arquivada de forma segura e de fácil acesso.

\section{Agradecimentos}

Toda a equipe do Cadastro de Fornecedores, equipe da Gestão Ambiental e Gestão da Qualidade.

\section{REFERÊNCIAS}

1 Yin RK. Estudo de caso: planejamento e métodos. 2a ed. Porto Alegre: Bookman; 2001.

\section{BIBLIOGRAFIA}

1 Ballou RH. Gerenciamento da Cadeia de Suprimentos: planejamento, organização e logística empresarial. 4 ${ }^{\mathrm{a}}$ ed. Porto Alegre: Brookman; 2001.

2 Chiavenato I. Administração de Materiais: uma abordagem introdutória. 3.ed. Rio de Janeiro: Elsevier; 2005.

3 Lima MP. Custos logísticos. In: Fleury PF, Figueiredo K, Wanke P. (Org.). Logística empresarial: a perspectiva brasileira. São Paulo: Atlas; 2000.

4 Tachiazawa T. Gestão ambiental e responsabilidade social corporativa. $7^{\mathrm{a}}$ ed. São Paulo: Atlas; 2011.

5 Viana JJ. Administração de materiais: um enfoque prático. São Paulo: Atlas; 2002.

6 Companhia Siderúrgica Nacional - CSN [página da internet]. Volta Redonda: CSN [acesso em 18 jan. 2013]. Disponível em: http://www.csn.com.br.

7 Sistema integrado de gestão empresarial. Wikipédia, a enciclopédia livre [acesso em: 09 jul. 2013]. Disponível em:

http://pt.wikipedia.org/w/index.php?title=Sistema_integrado_de_gest\%C3\%A3o_empres arial\&oldid=36513559.

\footnotetext{
* Contribuição técnica ao $33^{\circ}$ Seminário de Logística - Suprimentos, PCP, Transportes, 13 a 16 de
} maio de 2014, São Paulo, SP, Brasil. 